\title{
Business cycle and mortality in Spain
}

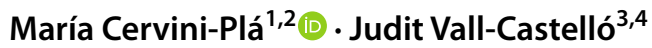

Received: 16 September 2020 / Accepted: 8 June 2021 / Published online: 23 June 2021

(c) The Author(s) 2021, corrected publication 2021

\begin{abstract}
In the last couple of decades, there has been a lot of interest on the impact of macroeconomic fluctuations on health and mortality rates. Many studies, for different countries, find that mortality is procyclical. However, studies examining the effects of more recent recessions are less conclusive, finding mortality to be less procyclical, or even countercyclical. In this paper, using data of Spanish provinces from 1999 to 2016, we investigate how this relationship works in the context of a country that is subject to extreme business cycle fluctuations. Furthermore, we analyze the impact of unemployment for different mortality causes and we explore differences by sex, age group and level of education. In general terms, we find mortality to be procyclical so that when the economy is in a recession, mortality falls. When exploring mortality causes, we show that deaths from cardiovascular disease, cancer, senility, transport accidents and homicides are procyclical. By sex, we find procyclicality for both men and women. By age, mortality is procyclical for all age groups; however, the causes of death that result in this procyclical behavior are specific to each age group. By educational level, suicide appears as a countercyclical cause for individuals with intermediate levels of education.
\end{abstract}

Keywords Mortality $\cdot$ Health $\cdot$ Recessions $\cdot$ Business cycle

JEL Classification E32 $\cdot \mathrm{I} 10 \cdot \mathrm{I} 12 \cdot \mathrm{I} 14 \cdot \mathrm{J} 14 \cdot \mathrm{J} 16$

\section{Introduction}

There is a widely interest among social science researches and policymakers in understanding the relationship between macroeconomic fluctuations and health, with a particular focus on mortality.

Aggregated time-series data by Brenner [1,2] disclosed that deaths by cardiovascular disease, cirrhosis, suicide and homicide, and infant mortality rates decrease when economic conditions improve. Nevertheless, the effects of business cycle conditions on mortality have become more controversial since the work by Ruhm [15], where he showed that mortality increases in periods of economic growth. In

María Cervini-Plá

maria.cervini@uab.cat

1 Universitat Autònoma de Barcelona, Edifici B. Campus UAB, Bellaterra (Cerdanyola del Vallès), 08193 Barcelona, Spain

2 EQUALITAS, Madrid, Spain

3 Universitat de Barcelona, Barcelona, Spain

4 CRES (UPF), Barcelona, Spain his paper, Ruhm combined time-series with cross-sectional data to better control for omitted variable bias.

In the last couple of decades, many studies have attempted to replicate these findings with the aim of understanding the specific causes that could explain this relationship using multiple techniques and datasets. However, the results of this large literature show ambiguous conclusions: on the one hand, there are many papers supporting the idea that mortality rates decrease during temporary economic recessions $[6,12-14,21,23,24]$ so that "recessions are good for your health". On the other hand, fewer studies reveal the opposite finding pointing towards health improvements during booms as suggested by the first papers on the literature in the 1970's [5, 20].

In 2008 Edwards [4] pointed towards the importance of the level of aggregation used for the analysis. He used both micro and macrolevel data and found that, when using aggregated data, the results show a procyclical relationship between mortality and business cycle fluctuations while at the individual level the results are more mixed depending on the subgroup of the population studied. Therefore, his findings highlight the fact that the level of analysis plays a 
crucial role in the sign of the relationship precisely because business cycle effects are heterogeneous across individuals. Therefore, the composition of the population plays an important role in defining the association at the macrolevel.

Another more recent paper that explore the oppositedirection effects of contextual and individual unemployment on mortality is Tapia Granados et al. [24]. They show how an increase in the unemployment rate correlates with a decrease in overall mortality or mortality due to most causes (procyclicality). However, at the same time, at the individual level, to suffer unemployment (because of being fired, plant closure or whatever) seems clearly connected with an increase in the risk of death. Using US data they find that compared to be employed, for those who experienced unemployment the hazard of death was increased by an amount equivalent to 10 extra years of age, and, at the same time, each percentage-point increase in the state unemployment rate (contextual unemployment) reduced the mortality hazard in all individuals by an amount equivalent to a reduction of 1 year of age. In line with this result at the microlevel, Sullivan and von Wachter [19] find that the risk of death is higher in individuals exposed to unemployment.

The recent recession that affected the global economy in 2008 marked a new opportunity to study this relationship. The new wave of papers looking at the relationship between mortality and business cycle conditions find even more diverging conclusions: some authors point towards a reduction in the previously documented procyclicality when using post-2008 data as compared to papers using pre-2008 data $[7,8,13,14,17]$ another group of authors find the relationship to be countercyclical $[9,11]$ while still a third group of authors report mortality to be unrelated to macroeconomic conditions [16].

Ruhm [16] suggests that changes in health behaviors such as the reduction in drinking, obesity, smoking and physical inactivity during recessions represent a credible and powerful mechanism that backs up the procyclicality argument. Cutler et al. [3] find that pollution also has explanatory power in the relationship between mortality and business cycle conditions as they report that, in places where pollution is low (i.e. agricultural economies), mortality rates are countercyclical. However, when pollution is important and is highly determined by the level of economic activity, mortality rates become procyclical. This finding is consistent with the work of Ionides et al. [10] showing that procyclical mortality is driven mostly by respiratory diseases and traffic injuries. Similarly, Strumpf et al. [18] estimate that increases in the local unemployment rates are associated with reductions in all-cause mortality rates and, $60 \%$ of this decrease, is explained by cardiovascular diseases. They also find reductions in motor vehicle fatalities during economic recessions, especially for men under age 65 . All these new papers strongly suggest the need to explore the contribution of each specific cause of death in order to fully understand the relationship between mortality and business cycle conditions.

Nonetheless, the factors explaining the divergence of findings in the literature are not entirely clear yet. Some authors have provided some examples: Ruhm [16] suggests that changes over time in the relationship between business cycle conditions and mortality may be driven by the fact that economic instability over time is poorly measured when using short periods of analysis. Another possible reason is the fact that the mechanisms behind the association between macroeconomic conditions and mortality may not be stable over time due to the changes in institutions or changes in health behaviors. Cutler et al. [3] also point in this direction, since they find that the intensity and even the direction of the relationship between mortality rates and macroeconomic conditions can be directly related to government spending levels. Going one step further, Stevens et al. [17] presents evidence that staff in nursing homes in the USA has a counter-cyclical behavior so that (at least part) of the mortality increases during booms can be explained by fluctuations in the quality of the health care provided.

Our paper contributes to this literature by examining the relationship between macroeconomic conditions and mortality in Spain, a country that has been severely hit by the recent economic crisis. Using very rich administrative data (mortality registers) covering the period 1999-2016, we link local (provincial) level unemployment rates to local level mortality rates while controlling for the age structure of the population, regional and time fixed effects, as well as regional trends. The strong variability in business cycle conditions over time in Spain (as seen in Fig. 1) represents a powerful element that strengthens the identification strategy and potentially allows us to increase the precision of the estimates. We believe that strong variations in the main explanatory variable in Spain vis-à-vis the relatively smaller variation in other developed countries previously studied in the literature is a comparative advantage that will help us better identify the relationship between business cycle conditions and mortality rates. We also explore the impacts for specific causes of death as well as differences by age, sex and educational level.

As far as we are aware, the Spanish case has been previously studied in Tapia Granados [22] and Regidor et al. [13, 14]. The paper by Tapia Granados [22] explores the relationship between economic conditions and mortality for Spain using data from 1980 to 1997 . His results show a procyclical relationship for the Spanish case although the size of the effects are smaller when compared to other countries: more specifically, he estimates a drop of $0.11 \%$ in mortality for a one percentage point increase in the local unemployment rate. Our paper presents several novelties with respect to Tapia Granados [22]. First, we include observations until 
30

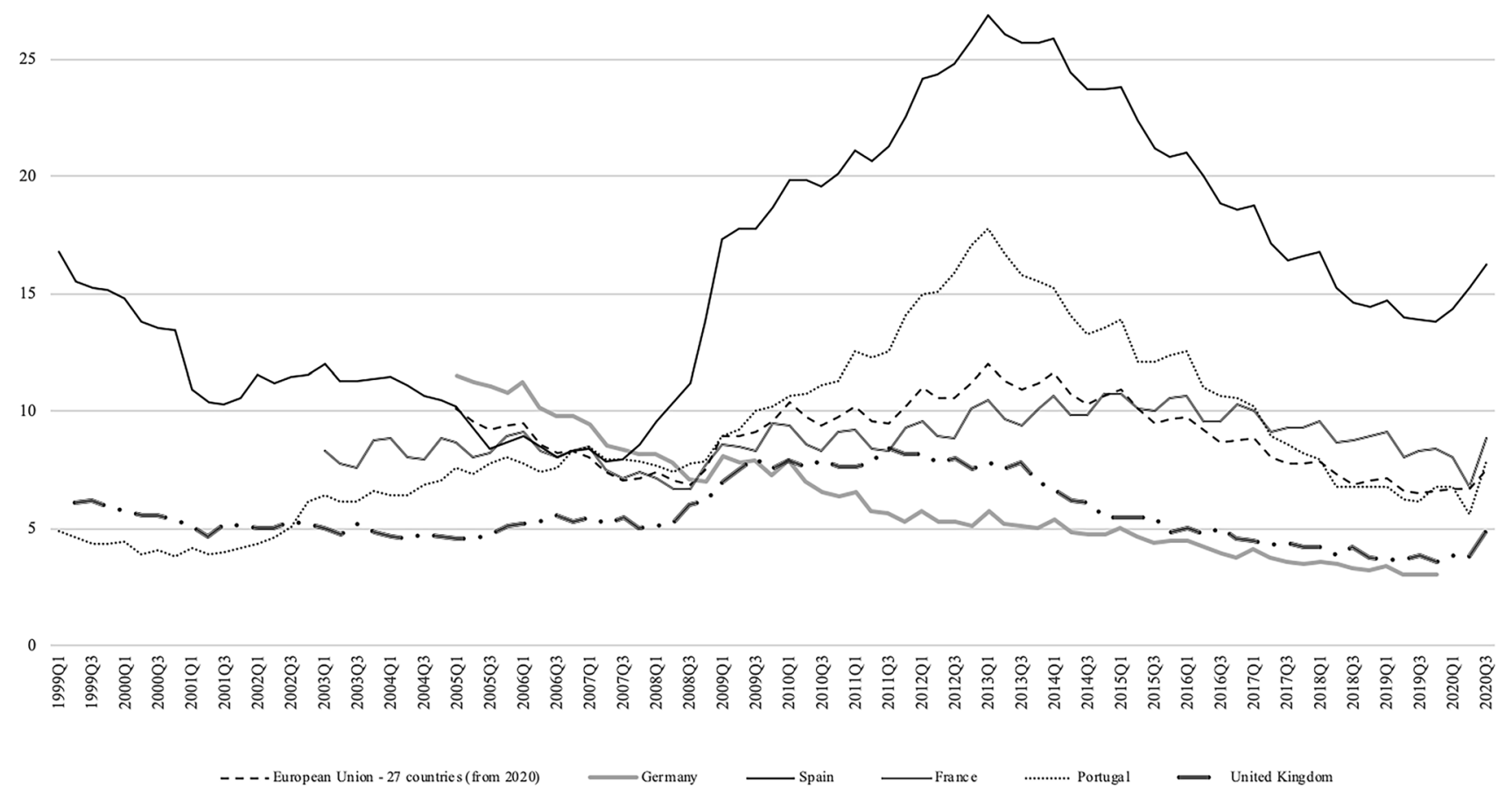

Fig. 1 Unemployment rates (1999-2013). Eurostat

2016 which allows us to capture the impacts of the recent economic crisis, which represented an unprecedented shock for the Spanish economy that raised unemployment rates over $25 \%$, as well as periods with an extremely booming economy (such as 2005-2007) with unemployment rates reaching minimum historical values below $10 \%$. Therefore, the effects that we find are much larger than those reported in Tapia Granados [22] as our results show that mortality reduces by $0.42 \%$ for a once percentage point increase in the local unemployment rate. Furthermore, having this updated information is also an important contribution to the recent literature as several papers have reported potential changes in the relationship between business cycle conditions and mortality in recent years. Our results show that, for the Spanish case, mortality is still strongly procyclical and this relationship has not changed in the recent years, as has been documented for other countries. On the contrary, the relationship has become larger as the coefficient in our estimates is larger than that reported in previous papers for Spain. Furthermore, we present a detailed analysis of the impact for several sources of death which allows us to better understand the mechanisms driving this relationship. Finally, we also focus on sex, age and educational differences that were previously undocumented.

More recently, we find two papers Regidor et al. [13, 14] that analyse the mortality rate in Spain before and during the
Great Recession, using Census data and following individuals until 2011. Regidor et al. [14] analyse mortality trends in different socioeconomic groups, quantifying the change within each group. They classified individuals by socioeconomic status (low, medium, or high) using two indicators of household wealth: household floor space and number of cars owned by the residents of the household. They find that in all socioeconomic groups, the all-cause mortality rate declined more during the first 4 years of the crisis period (2008-11) than in the 4 years receding the crisis (2004-07), except for women in the high socioeconomic group, whose mortality declined less during the crisis. Exploring causespecific mortality rates, they show a similar pattern, except for cancer in all women and for traffic and other unintentional injuries in women in the high socioeconomic group. Furthermore, the acceleration of the downward linear trend in mortality was higher in the lowest socioeconomic group than in the highest group for all-cause deaths and for most of the specific causes of death analysed. Regidor et al. [13] analyse mortality rates for employed, unemployed and inactive individuals. They find that for employed and unemployed men, mortality rates increased until 2007 and then declined, whereas in employed and unemployed women, mortality rates increased and then stabilized during 2008-2011. The mortality rate among inactive men and women decreased throughout the follow-up. Thus, they find that during the 
economic crisis, the upward trend in the rate of mortality from all diseases was inverted in the groups of employed and unemployed subjects at baseline. Compared with these two interesting most recent papers, our article provides a longer period, a record of all the people who have died in Spain and a detailed analysis by age and educational level.

Our results suggest that, when the economy is in a recession, mortality rate falls. This result is consistent with the findings in Tapia Granados [22] and suggests that the relationship between business cycle conditions and mortality has not changed in the last 30 years. Additionally, our study detects that, while cardiovascular deaths, senility diseases, cancer and deaths by transport accidents are procyclical, countercyclical patterns emerge for suicide and diabetes. With respect to sex differences, our results show that men are significantly more affected by transport accidents than women in Spain. Although mortality is procyclical for all age groups, the causes that lead this pro-cyclicality are different in each age segment. Finally, suicide appears as a countercyclical cause for intermediate education levels.

This paper is organized as follows. "Methodology" section presents our methodology. "Data and descriptive statistics" section explains the dataset used and our sample selection. "Results" section shows the main results and "Heterogeneous effects" section explores heterogeneities by sex, age and education. Finally, "Conclusion" section concludes.

\section{Methodology}

To analyse the relationship between macroeconomic conditions and mortality rates, we follow very close Ruhm [16]. Our dependent variable is the mortality rate calculated as the number of deaths in a particular cell (we use different definitions of a cell) divided by the population in that particular cell. More specifically, we estimate the following equation:

$$
\begin{aligned}
\ln \left(M_{k j t}\right)= & \alpha_{k j}+U_{k j t} \gamma+\lambda_{k t}+H_{j} * t+A 15_{j t} \eta \\
& +A 65_{j t} \delta+\epsilon_{k j t}
\end{aligned}
$$

where $M_{k j t}$ is the mortality rate from diseases $k$ in province $j$ at certain moment of time $t, U$ is the unemployment rate in that province at that time (a proxy of the economic conditions), $\alpha$ are province fixed-effects that control for timeinvariant province characteristics (such as persistent lifestyle disparities between residents of two different provinces), $\lambda$ accounts for calendar time fixed effects (which capture any determinant of mortality that vary over time but in the same way across provinces: e.g. advances in widely used medical technologies or behavioural norms), $H_{j} * t$ is a provincespecific linear trend and $\epsilon$ is the error term. Therefore, $\gamma$ is our parameter of interest and captures the effects of the cycle on mortality. Finally, we acknowledge that the age structure is an important determinant of total mortality and mortality due to specific causes. Thus, to control for the demographic structure of the population and any potential changes over time (that might not be fully captured by the province-specific linear trends), we also include as demographic controls the proportion of the population above 65 years old $A 65_{j t}$ as well as the proportion of the population below 15 years old $A 15_{j t}$. In that way, the results of the model reflect how age-adjusted mortality responds to the changes in economic conditions.

To estimate the relative effects we can estimate, following the same idea than Ruhm [16]:

$\left(e^{\hat{\gamma} k}-1\right) * 100 \%$

This expression gives us the predicted percentage change in mortality from source $k$ resulting from a one percentage point increase in the unemployment rate. These relative effects are translated into absolute numbers through estimates of:

$\left(e \Delta^{\hat{\gamma} k}-1\right) * \pi_{k} D$,

where $\Delta^{\hat{\gamma} k}=\hat{\gamma}_{2 k}-\hat{\gamma}_{1 k}$ and $\pi_{k}$ is the share of deaths due to source $k$ and $D$ is the average annual number of deaths $(384,710)$.

In particular, we estimate Eq (1) for the total mortality rate and by specific mortality causes using annual data by province. Furthermore, we explore differences in the impact of business cycle conditions on annual mortality rates by sex, age groups and educational level using group-specific outcomes.

We consider 52 geographic units that, for simplicity, we call provinces. However, strictly speaking what we include corresponds to 50 provinces plus Ceuta and Melilla, that are autonomous cities. All regressions are weighted by the squared root of the population in each geographic unit and time, and standard errors are clustered by geographic unit.

\section{Data and descriptive statistics}

As an indicator of macroeconomic conditions, we use the unemployment rate. We obtain annual and quarterly unemployment rate information for each province from the National Institute of Statistics in Spain (INE).

We use mortality registers for the period 1999-2016 also from the INE. The restricted access version of the files allow us to include information on the type of diseases that caused the death. The registers are collected at the individual level and include all deaths in Spain from 1990 to 2016, the diseases that caused the death and some individual characteristics such as sex, age, education and province of the person that died. We collapse the individual information by 
province for each year to get the number of individuals dying in each province and time period. We aggregate the information for total mortality but also for different causes of death. To do the analysis of cause-specific mortality we classify the different mortality causes in 12 categories: cardiovascular, cancer, respiratory, senility, Alzheimer, diabetes, digestive, other diseases, transport accidents, other accidents, suicides and homicides. To calculate mortality rates, we divide the number of deaths by the population (and multiply it by 1000), using information on population numbers in the same province and year.

In addition to total annual mortality rates for each province, we construct sex-specific death rates, mortality rates for five age groups $(<25,25-44,45-64,65-74,>74)$, as well as by level of education for those aged over 25 years old (we only have information about education from 2012 onwards).

Table 5 in Appendix presents information, for each of the years included in our database, on the total number of people dying (total mortality), the total number of individuals (population) and the mortality rate. As can be seen in the table, both the number of people who die and the total population is increasing in our period. However, the mortality rate has more volatility and it is increasing in some periods and decreasing in others. Figure 2 shows the evolution of the mortality rate and the unemployment rate in Spain from 1999 to 2016. The relationship between the two variables is not clear; while in the first period it seems that both variables move in parallel, after the crisis it looks like they go in opposite directions, recovering a the parallel path in the last years of the analyzed period.

Table 6 in Appendix shows some descriptive statistics of our sample. With respect to the causes of death, we can observe that the most common causes of death are: cardiovascular problems, cancer and respiratory problems. As for age, we can see that the proportion of individuals dying is highly concentrated in the oldest age group. More than 70\% of the deaths occur for people who have more than 75 years old. Regarding the level of education, most of individuals in our sample have a relatively low level of education. This is due to the fact that the education level of the elderly is much lower than the average for the entire population.

Figure 3 in the Appendix shows the evolution of the different mortality causes in the period analyzed. On the left panel we can see a slight reduction in deaths from cardiovascular problems, an increase in cancer mortality and diseases associated with an aging population such as senility and Alzheimer. On the right hand side of the panel, we can see a continuous reduction in traffic accidents throughout the period, which coincides with an increased governmental effort to raise public awareness on the importance of enforcing traffic rules. Other types of accidents are increasing during the period and suicides appear to have increased after the crisis.

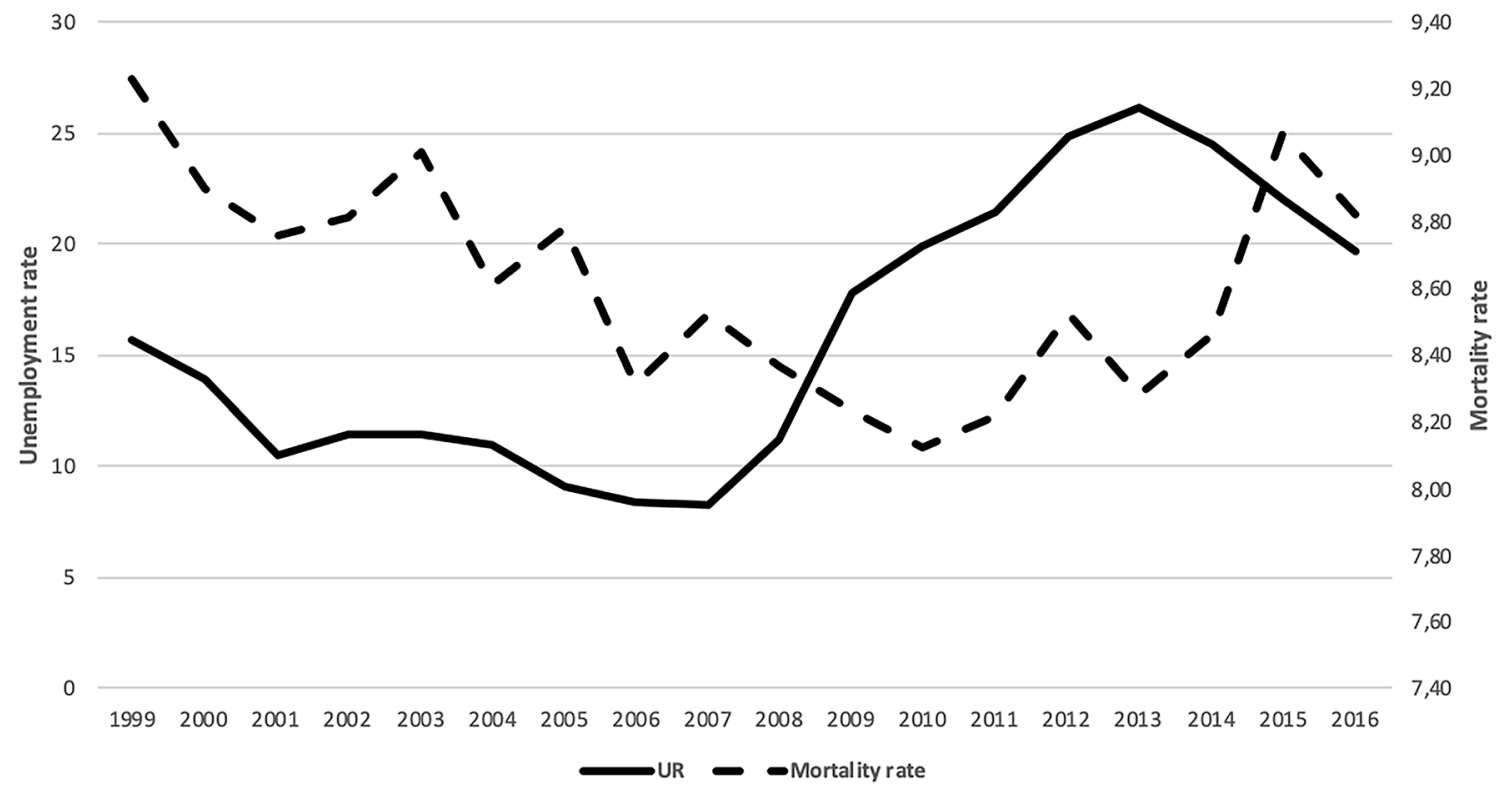

Fig. 2 Mortality rate and unemployment rate 


\section{Results}

In the first row of Table 1, we examine the relationship between economic conditions and total mortality rates with annual information. Our parameter of interest, the local level unemployment rate, has a significant and negative coefficient. Thus, we find a procyclical relationship between business cycle conditions and mortality in Spain during our sample period. That is, once long-term trends are adjusted for, when the local unemployment rate increases because the economy is in a recession, mortality falls. We find that a one percentage point increase in the local unemployment rate reduces the mortality rate by $0.42 \%$. The estimation include year and province fixed effect, linear trends, and age controls.

In the following rows of Table 1, we present separate results for each of the 12 categories of cause-specific mortality. We find that some causes are strongly and significantly procyclical, such as cardiovascular diseases, cancer, senility diseases, transport accidents and homicide. Another group of diseases have a negative sign but the coefficient is only significant at the $10 \%$ level, such as respiratory diseases or other accidents. We also find that a number of diseases show a counter-cyclical relationship with business cycle conditions, but not significant, such as Alzheimer and diabetes. Some of these relationships have been found in papers looking at the same question in other countries $[15,16]$. Therefore, some of the sources of deaths seem to be procyclical

Table 1 Effect of a one percentage point increase in the unemployment rate on the mortality rate due to all causes

\begin{tabular}{lll}
\hline Mortality rate & Effect & Standard error \\
\hline All causes & $-0.0042^{* * *}$ & $(0.0009)$ \\
Cardiovascular & $-0.0072^{* * *}$ & $(0.0017)$ \\
Cancer & $-0.0022^{* * *}$ & $(0.0008)$ \\
Respiratory & $-0.0025^{*}$ & $(0.0015)$ \\
Senility & $-0.0146^{* * *}$ & $(0.0036)$ \\
Alzheimer & 0.0001 & $(0.0023)$ \\
Diabetes & 0.0006 & $(0.0061)$ \\
Digestive & -0.0039 & $(0.0027)$ \\
Other diseases & -0.0021 & $(0.0018)$ \\
Transport accidents & $-0.0147^{* * *}$ & $(0.0039)$ \\
Other accidents & $-0.0088^{*}$ & $(0.0044)$ \\
Suicide & -0.0035 & $(0.0025)$ \\
Homicide & $-0.0239^{* *}$ & $(0.0110)$ \\
Men & $-0.0041^{* * *}$ & $(0.0008)$ \\
Women & $-0.0025^{* * *}$ & $(0.0007)$ \\
\hline
\end{tabular}

Number of observations: 936. All estimations include Year FE, Province FE, Linear trends and demographic controls

Robust standard errors in parentheses, $* * * p<0.01, * * p<0.05$, * $p<0.1$ across several countries and this is particularly the case for transport accidents and cardiovascular diseases. At the macrolevel, our data (and the majority of the previous literature) seems to support the idea that in times of economic booms, and higher employment probabilities, there are more cardiovascular deaths. As we mentioned in the introduction, Tapia Granados et al. [24] explore the paradox between what is found at the micro and macroeconomic levels. Although it is true that higher unemployment at the individual level can generate more mortality associated with greater stress, at the macrolevel, a higher unemployment rate is associated (in most countries) with lower mortality from most causes (including cardiovascular). For example, the reduction in mobility leads to a lower number of transport accidents.

\section{Heterogeneous effects}

In the last two rows of Table 1, we present results separately for men and women using annual data. We find a statistically significant procyclical coefficient for both, men and women. For the case of men, we estimate that a one percentage point increase in unemployment leads to a reduction in mortality by $0,41 \%$. For women the coefficient is also negative but somewhat smaller; a one percentage point increase in the unemployment rate is associated with a reduction of $0.25 \%$ in mortality.

Table 7 in the Appendix presents the results by sex for the different causes. For men, we find that the coefficients that appear most significant are cardivascular, cancer, senility and transport accidents. These coefficients have a negative sign, which shows a procyclical relationship. When unemployment increases in a recession, deaths due to cardiovascular problems decrease partly because individuals are exposed to less job-related stress and eating habits improved due to more home cooked meals. At the same time, as mobility is reduced during unemployment spells, there are lower deaths due to transport accidents. For the case of women, we observe the same pattern but the estimated coefficients are somewhat smaller. Some causes are only significant either for men or for women. For example, we find that the coefficient of homicides and other accidents is significant and negative (showing procyclicality) for men. While in the case of women we find procyclicality in deaths from digestive diseases.

A second exploration exercise that we are interested in this article is to analyse the differences in the cyclicality of mortality by age group. As we explained in the descriptive section, we have five age groups $(<25,25-44,45-64$, $65-74,>74)$. In Table 2 we can see that, for all age groups, we find strong evidence that mortality is procyclical and significant. That means that, when unemployment increases, mortality decreases and vice versa. However, there are 
Table 2 Effects on age-specific mortality rates associated with a one-percentage point increase in the unemployment rate

\begin{tabular}{llllll}
\hline Mortality rate & $0-25$ & $25-44$ & $45-64$ & $65-74$ & $>74$ \\
\hline Unemployment & $-0.0079 * *$ & $-0.0024 * *$ & $-0.0032^{* *}$ & $-0.0042^{* * *}$ & $-0.0029^{* * *}$ \\
& $(0.0026)$ & $(0.0011)$ & $(0.0015)$ & $(0.0011)$ & $(0.0010)$ \\
Observations & 936 & 936 & 936 & 936 & 936 \\
R-squared & 0.8773 & 0.8618 & 0.9889 & 0.9960 & 0.9994 \\
\hline
\end{tabular}

All estimations include Year FE, Province FE, Linear trends

Robust standard errors in parentheses, $* * * p<0.01$, ** $p<0.05, * p<0.1$

\begin{tabular}{llllll}
\hline Mortality rate & Less primary & Primary & Secondary & High school & University \\
\hline Unemployment & $0.0007(0.0021)$ & $0.0023(0.0014)$ & $0.0001(0.0016)$ & $0.0021(0.0029)$ & $0.0034(0.0026)$ \\
Observations & 260 & 260 & 260 & 260 & 260 \\
R-squared & 0.9939 & 0.9960 & 0.9966 & 0.9633 & 0.9716 \\
\hline
\end{tabular}

All estimations include Year FE, Province FE, Linear trends and demographic controls

Robust standard errors in parentheses, $* * * p<0.01$, ** $p<0.05, * p<0.1$
Table 3 Effects on the death rate of groups of different educational level associated with a one-percentage point increase in the unemployment rate
Table 4 Predicted number of deaths

important differences in the causes that lead this procyclicality, which vary for each age group.

In Table 8 in the Appendix, we explore the results by age group and for different causes of deaths. There is considerable heterogeneity across different sources of deaths. For those under the age of 25 (which we can observe in more detail in the first column of the table), there are three coefficients that have a negative and significant sign (evidence of prociclicality): deaths due to cardiovascular diseases, other diseases and transport accidents. However, it is important to mention that cardiovascular diseases are not important in this age group. In the age group 25-44, as we can observe in the second column, we do not find any significant coefficient. In the third column we show the results for individuals aged 45-64 and we find a negative coefficient in the following mortality causes: cardiovascular, respiratory diseases, diabetes, other diseases and transport accidents. For the age group 65-74 (column 4), we can see a negative coefficient in deaths due to cardiovascular problems and respiratory diseases. Finally, we present detailed results for those over 74 and we obtain a significant and negative coefficient for: cardiovascular problems, digestive and other diseases. Therefore, although mortality is procyclical for all age groups, the causes that lead this procyclicality are somewhat different for the different age segments.

A third heterogeneity exercise that we implement distinguishes across different levels of education. We classify individuals according to the highest level of education that they have obtained. As we only want to include those individuals that have already completed their desired level of education, we restrict the sample to those aged over 25 years

\begin{tabular}{lll}
\hline Population sub-group & Number of deaths & 95\%Conf. interval \\
\hline All death & $-1612 * * *$ & $-936,-2288$ \\
Males & $-801 * * *$ & $-495,-1107$ \\
Females & $-472 * * *$ & $-213,-730$ \\
Cardiovascular for all & $-805 * * *$ & $-434,-1176$ \\
Cancer & $-232 * * *$ & $-67,-398$ \\
Transport accidents & $-28 * * *$ & $-14,-43$ \\
Homicide & $-9 * *$ & $-1,-17$ \\
\hline
\end{tabular}

To calculate the predicted number of death we use $\left(e^{\hat{\gamma} k}-1\right) \cdot \pi_{k} D$ where $\pi_{k}$ is the share of deaths

due to source $\mathrm{k}$ and $D$ is the average annual number of deaths $(384,710)$

95\% confidence intervals are estimated as $\left(e^{\hat{\gamma} k \pm 1.96 \cdot s_{k}}-1\right) x \pi_{k} D$ for $s_{k}$ standard error

$* * * \mathrm{p}<0.01, * * \mathrm{p}<0.05$

old. Unfortunately we only have this information from 2012 onwards. In our dataset, we can distinguish between five education levels: less than primary school, primary school, secondary, high school and university. As we can see in Table 3, we do not obtain any significant coefficient for the regressions of all cause mortality by different educational groups. However, when analyzed by cause, in Table 9 in the Appendix, we observe that suicides show a countercyclical pattern, as they increase during crises periods and decrease in moments of expansion, for individuals with an intermediate level of education. 
Finally, an important exercise is to calculate how much these coefficients represent in terms of the number of deaths. Table 4 shows that a one percentage point increase in the unemployment rate decreases the total number of deaths by, on average, 1612 per year (with a $95 \%$ confidence interval ranging from 936 deaths to 2288). By sex, the prediction of the effect of a 1 point increase in the unemployment rate for men is higher (801 fewer deaths) than for women (472 fewer deaths). By causes, the main cause that decreases in a recession is cardiovascular deaths; a 1 point increase in the unemployment rate decreases cardiovascular deaths by 805 per year. Finally, we can also predict that a 1 point increase in the unemployment rate decreases cancer death by 232 , transport accidents death by 28 and homicides by 9 per year.

\section{Conclusion}

This paper shows that, during the period 1999-2016, mortality exhibits a procyclical pattern in Spain; that is, when the local unemployment rate increases mortality falls. Exploring the impact of unemployment for different mortality causes we show that deaths from cardiovascular disease, cancer, senility and transport accidents are strongly procyclical. However, countercyclical patterns have emerged for diabetes and suicide.

When we study the effects by sex, we see that, for both men and women the coefficient is negative (procyclicality) although the effects for men are somewhat higher. Again, cardiavascular, senility and transport accident causes seem to lead that procyclicality. Mortality is procyclical for all the age groups analysed; however, the causes that foster this procyclicality are slightly different in each age group. For example, for those between 45 and 65 respiratory problems and transport accidents explain the procyclicality pattern. On the other hand, procyclicity of deaths due to cardiovascular problems appear in a significant manner in all age groups (except those of 25-45). By educational level, suicide appears as a countercyclical cause (increasing in recessions and decreasing in the growing seasons) for individuals with intermediate education levels.

We believe that our paper provides new evidence on the relationship between business cycle conditions and mortality with respect to the previous literature. More specifically, our data allows us to study this relationship for a more recent period and for a country that has been exposed to an extremely strong recession in the mid-2008. With respect to the article of Tapia Granados [22], we are able to explore a more recent period, which allows us to capture the impacts of the recent economic crisis. As our results are consistent with his findings, we are confident when concluding that the sign and significance levels of the relationship between business cycle conditions and mortality in Spain has not changed in the last 30 years. However, we report that the effect of the business cycle on mortality has become larger in more recent years, as the coefficient in our estimates is larger than that reported in the previous papers for Spain.

Compared with Regidor et al. [13, 14] our article uses administrative data derived from the mortality registers, which is available for every year included in our study and, therefore, allows us to include a longer period of time than Regidoret al. [13, 14], which use Census data. Furthermore, we are able to present a detailed analysis of the impact for several sources of death, which allows us to better understand the mechanisms driving this relationship, as well as a detailed analysis by sex, age and education, that was previously undocumented.

\section{Appendix}

See Appendix Table 5, Fig. 3, and Tables 6, 7, 8, 9.

Table 5 Total number of deaths, population and mortality rate (per thousand population)

\begin{tabular}{llll}
\hline Year & Deaths & Population & Mortality rate \\
\hline 1999 & 371,102 & $40,202,160$ & 9.23 \\
2000 & 360,391 & $40,499,791$ & 8.90 \\
2001 & 360,131 & $41,116,842$ & 8.76 \\
2002 & 368,618 & $41,837,894$ & 8.81 \\
2003 & 384,828 & $42,717,064$ & 9.01 \\
2004 & 371,934 & $43,197,684$ & 8.61 \\
2005 & 387,355 & $44,108,530$ & 8.78 \\
2006 & 371,478 & $44,708,964$ & 8.31 \\
2007 & 385,361 & $45,200,737$ & 8.53 \\
2008 & 386,324 & $46,157,822$ & 8.37 \\
2009 & 384,933 & $46,745,807$ & 8.23 \\
2010 & 382,047 & $47,021,031$ & 8.13 \\
2011 & 387,911 & $47,190,493$ & 8.22 \\
2012 & 402,950 & $47,265,321$ & 8.53 \\
2013 & 390,419 & $47,129,783$ & 8.28 \\
2014 & 395,830 & $46,771,341$ & 8.46 \\
2015 & 422,568 & $46,624,382$ & 9.06 \\
2016 & 410,611 & $46,557,008$ & 8.82 \\
\hline
\end{tabular}



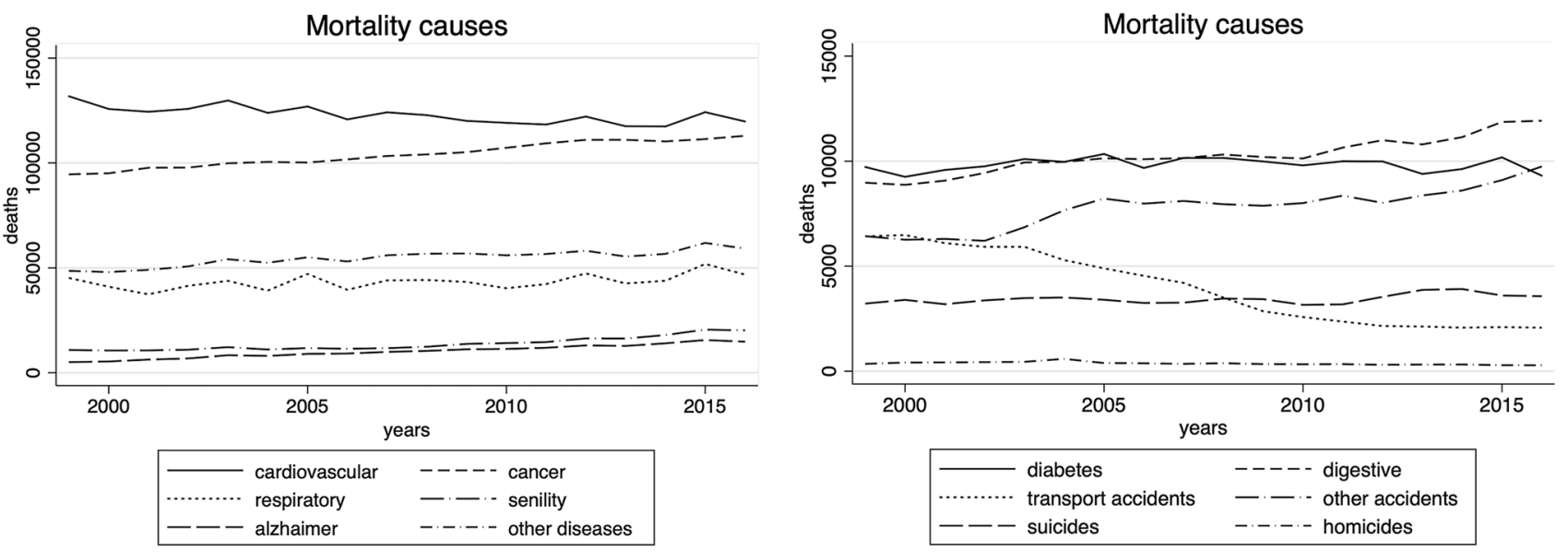

Fig. 3 Evolution mortality causes

Table 6 Proportions of deaths in total mortality by cause of death or characteristic of the deceased Source: Spanish mortality registers 1999-2016, Spanish National Institute of Statistics

\begin{tabular}{|c|c|}
\hline Characteristic & Percentage \\
\hline \multicolumn{2}{|l|}{ Sex } \\
\hline Men & 50.9 \\
\hline Women & 49.1 \\
\hline \multicolumn{2}{|l|}{ Causes } \\
\hline Cardiovascular & 29.2 \\
\hline Cancer & 27.5 \\
\hline Respiratory & 11.4 \\
\hline Senility & 4.9 \\
\hline Alzheimer & 3.6 \\
\hline Diabetes & 2.3 \\
\hline Digestive & 2.9 \\
\hline Other diseases & 14.4 \\
\hline Transport accidents & 0.5 \\
\hline Other accidents & 2.4 \\
\hline Suicides & 0.9 \\
\hline Homicides & 0.1 \\
\hline \multicolumn{2}{|l|}{ Age } \\
\hline$<25$ & 0.6 \\
\hline $25-44$ & 1.8 \\
\hline $45-64$ & 11.5 \\
\hline $65-74$ & 13.3 \\
\hline$>74$ & 72.8 \\
\hline \multicolumn{2}{|l|}{ Education } \\
\hline Less than primary school & 27.8 \\
\hline Completed primary school & 34.9 \\
\hline Compulsory secondary education (ESO) & 19.9 \\
\hline High school and vocational education & 8.1 \\
\hline University degree & 9.3 \\
\hline
\end{tabular}

Table 7 Effect on different causes by sex

\begin{tabular}{llc}
\hline Diseases & Men & Women \\
\hline Cardiovascular & $-0.0066^{* * *}$ & $-0.0050^{* * *}$ \\
Cancer & $-0.0019^{* *}$ & $-0.0014^{* *}$ \\
Respiratory & -0.0024 & -0.0004 \\
Senility & $-0.0148^{* * *}$ & $-0.0101^{* * *}$ \\
Alzheimer & -0.0013 & 0.0003 \\
Diabetes & -0.0002 & 0.0026 \\
Digestive & -0.0023 & $-0.0042^{* *}$ \\
Other diseases & $-0.0038^{* *}$ & -0.0009 \\
Transport accidents & $-0.0188^{* * *}$ & $-0.0145^{* * *}$ \\
Other accidents & $-0.0080^{* *}$ & 0.0020 \\
Suicide & -0.0042 & 0.0053 \\
Homicide & $-0.0352^{* *}$ & -0.0217 \\
\hline
\end{tabular}

Number of observations: 936 for each estimation. All estimations include Year FE, Province FE, Linear trends and demographic controls

Robust standard errors in parentheses, $* * * p<0.01$, ** $p<0.05$, * $p<0.1$ 
Table 8 Different cause by age group

\begin{tabular}{lccccc}
\hline Diseases & \multicolumn{1}{l}{ 0-25 } & \multicolumn{1}{l}{ 25-44 } & \multicolumn{1}{l}{$45-64$} & $65-74$ & $>74$ \\
\hline Cardiovascular & $-0.0288^{*}$ & -0.0035 & $-0.0079 * * *$ & $-0.0090^{* * *}$ & $-0.0067^{* * *}$ \\
Cancer & 0.0040 & 0.0014 & 0.0025 & 0.0010 & 0.0003 \\
Respiratory & -0.0027 & -0.0049 & $-0.0067 * *$ & $-0.0043^{*}$ & -0.0008 \\
Senility & -0.0045 & 0.0043 & 0.0113 & -0.0024 & -0.0016 \\
Alzheimer & 0.0000 & -0.0136 & 0.0184 & -0.0051 & 0.0020 \\
Diabetes & -0.0039 & 0.0259 & $-0.0109 *$ & -0.0047 & -0.0011 \\
Digestive & -0.0257 & 0.0140 & -0.0009 & -0.0002 & $-0.0039^{*}$ \\
Other diseases & $-0.0100^{* *}$ & -0.0033 & $-0.0082^{* * *}$ & $-0.0049 * *$ & $-0.0031^{* *}$ \\
Transp Acc. & $-0.0142^{* *}$ & 0.0059 & $-0.0143^{* * *}$ & -0.0093 & $-0.0098^{*}$ \\
Other Acc. & -0.0113 & -0.0010 & -0.0063 & 0.0027 & 0.0064 \\
Suicide & -0.0019 & -0.0005 & $-0.0100^{* *}$ & -0.0054 & $-0.0073^{*}$ \\
Homicide & -0.0102 & -0.0088 & -0.0141 & -0.0077 & 0.0074 \\
\hline
\end{tabular}

Number of observations: 936 for each estimation. All estimations include Year FE, Province FE, Linear trends

Robust standard errors in parentheses, $* * * p<0.01, * * p<0.05, * p<0.1$
Table 9 Different cause by education

\begin{tabular}{lrrrrr}
\hline Diseases & Less primary & Primary & Secondary & High school & University \\
\hline Cardiovascular & 0.0010 & 0.0030 & -0.0004 & -0.0007 & 0.0085 \\
Cancer & -0.0040 & 0.0015 & -0.0042 & $0.0081^{*}$ & -0.0015 \\
Respiratory & 0.0052 & 0.0021 & -0.0030 & -0.0049 & -0.0003 \\
Senility & 0.0137 & 0.0046 & 0.0030 & 0.0135 & -0.0186 \\
Alzheimer & 0.0033 & -0.0052 & 0.0145 & 0.0193 & 0.0134 \\
Diabetes & -0.0004 & 0.0164 & 0.0217 & -0.0161 & 0.0403 \\
Digestive & 0.0055 & 0.0088 & 0.0111 & -0.0406 & 0.0109 \\
Other diseases & -0.0016 & -0.0027 & 0.0031 & -0.0009 & 0.0021 \\
Transp Acc. & -0.0237 & 0.0209 & 0.0043 & -0.0099 & $-0.1208^{*}$ \\
Other Acc. & -0.0078 & 0.0066 & 0.0261 & 0.0013 & -0.0012 \\
Suicide & 0.0059 & 0.0345 & 0.0175 & $0.0779 * *$ & 0.0146 \\
Homicide & -0.1023 & 0.0564 & 0.1237 & 0.1857 & 0.0254 \\
\hline
\end{tabular}

Number of observations: 936 for each estimation. All estimations include Year FE, Province FE, Linear trends and demographic controls

Robust standard errors in parentheses, *** $p<0.01$, ** $p<0.05$, * $p<0.1$
Funding Open Access funding provided thanks to the CRUE-CSIC agreement with Springer Nature.

Open Access This article is licensed under a Creative Commons Attribution 4.0 International License, which permits use, sharing, adaptation, distribution and reproduction in any medium or format, as long as you give appropriate credit to the original author(s) and the source, provide a link to the Creative Commons licence, and indicate if changes were made. The images or other third party material in this article are included in the article's Creative Commons licence, unless indicated otherwise in a credit line to the material. If material is not included in the article's Creative Commons licence and your intended use is not permitted by statutory regulation or exceeds the permitted use, you will need to obtain permission directly from the copyright holder. To view a copy of this licence, visit http://creativecommons.org/licenses/by/4.0/.

\section{References}

1. Brenner, M.: Trends in alcohol consumption and associated illnesses. Some effects of economic changes. Am. J. Public Health 65(12), 1279-1292 (1975)

2. Brenner, M.: Mortality and the national economy. A review, and the experience of England and Wales, 1936-76. Lancet 2(8142), 568-573 (1979)

3. Cutler, D. M., Huang, W., Lleras-Muney, A.: Economic Conditions and Mortality: Evidence from 200 Years of Data. NBER Working Papers 22690, National Bureau of Economic Research, Inc (2016)

4. Edwards, R.: Who is hurt by procyclical mortality? Soc. Sci. Med. 67(12), 2051-2058 (2008)

5. Gerdtham, U., Johannesson, M.: Business cycles and mortality: results from Swedish microdata. Soc. Sci. Med. 60(1), 205-218 (2005) 
6. Gerdtham, U., Ruhm, C.J.: Deaths rise in good economic times: Evidence from the OECD. Econ. Hum. Biol. 4(3), 298-316 (2006)

7. Gonzalez, F., Quast, T.: Macroeconomic changes and mortality in Mexico. Empir. Econ. 40(2), 305-319 (2011)

8. Haaland, V.F., Telle, K.: Pro-cyclical mortality across socioeconomic groups and health status. J. Health Econ. 39(C), 248-258 (2015)

9. Halliday, T.J.: Unemployment and mortality: Evidence from the PSID. Soc. Sci. Med. 113(C), 15-22 (2014)

10. Ionides, E., Wang, Z., Tapia Granados, J.: Macroeconomic effects on mortality revealed by panel analysis with nonlinear trends. Ann. Appl. Stat. 7(3), 1362-1385 (2013)

11. McInerney, M., Mellor, J.M.: Recessions and seniors' health, health behaviors, and healthcare use: Analysis of the Medicare Current Beneficiary Survey. J. Health Econ. 31(5), 744-751 (2012)

12. Neumayer, E.: Recessions lower (some) mortality rates: evidence from Germany. Soc. Sci. Med. 58(6), 1037-1047 (2004)

13. Regidor, E., Ronda, E., Tapia Granados, J.A., Pulido, J., de la Fuente, L., Barrio, G.: Reversal of upward trends in mortality during the great recession by employment status at baseline in a national longitudinal study. Am. J. Epidemiol. 188(11), 2004-2012 (2019)

14. Regidor, E., Vallejo, F., Granados, J.A.T., Viciana-Fernández, F.J., de la Fuente, L., Barrio, G.: Mortality decrease according to socioeconomic groups during the economic crisis in spain: a cohort study of 36 million people. Lancet 388(10060), 2642$2652(2016)$
15. Ruhm, C.J.: Are Recessions Good for Your Health? Q. J. Econ. 115(2), 617-650 (2000)

16. Ruhm, C.J.: Recessions, healthy no more? J. Health Econ. 42(C), 17-28 (2015)

17. Stevens, A.H., Miller, D.L., Page, M.E., Filipski, M.: The best of times, the worst of times: understanding pro-cyclical mortality. Am. Econ. J. Econ. Policy 7(4), 279-311 (2015)

18. Strumpf, E.C., Charters, T.J., Harper, S., Nandi, A.: Did the Great Recession affect mortality rates in the metropolitan United States? Effects on mortality by age, gender and cause of death. Soc. Sci. Med. 189(C), 11-16 (2017)

19. Sullivan, D., von Wachter, T.: Job displacement and mortality: an analysis using administrative data. Q. J. Econ. 124(3), 1265-1306 (2009)

20. Svensson, M.: Do not go breaking your heart: Do economic upturns really increase heart attack mortality? Soc. Sci. Med. 65(4), 833-841 (2007)

21. Tapia Granados, J.: Increasing mortality during the expansions of the US economy, 1900-1996. Int. J. Epidemiol. 34, 1194-1202 (2005)

22. Tapia Granados, J.: Recessions and mortality in spain, 1980-1997. Eur. J. Popul. 21(4), 393-422 (2005)

23. Tapia Granados, J.: Macroeconomic fluctuations and mortality in postwar Japan. Demography 45(2), 323-343 (2008)

24. Tapia Granados, J.A., House, J.S., Ionides, E.L., Burgard, S., Schoeni, R.S.: Individual joblessness, contextual unemployment, and mortality risk. Am. J Epidemiol. 180(3), 280-287 (2014) 